桨9g gso

PPPL-2833

UC-426
PREPARED FOR THE U.S. DEPARTMENT OF ENERGY, UNDER CONTRACT DE-AC02-76-CHO-3073

PPPL-2833

CALCULATION OF CHARGED FUSION PRODUCT DISTRIBUTIONS IN SPACE, ENERGY, AND TIME

BY

J. SCHIVELL, D.A. MONTICELLO, AND S.J. ZWEBEN

February 1992
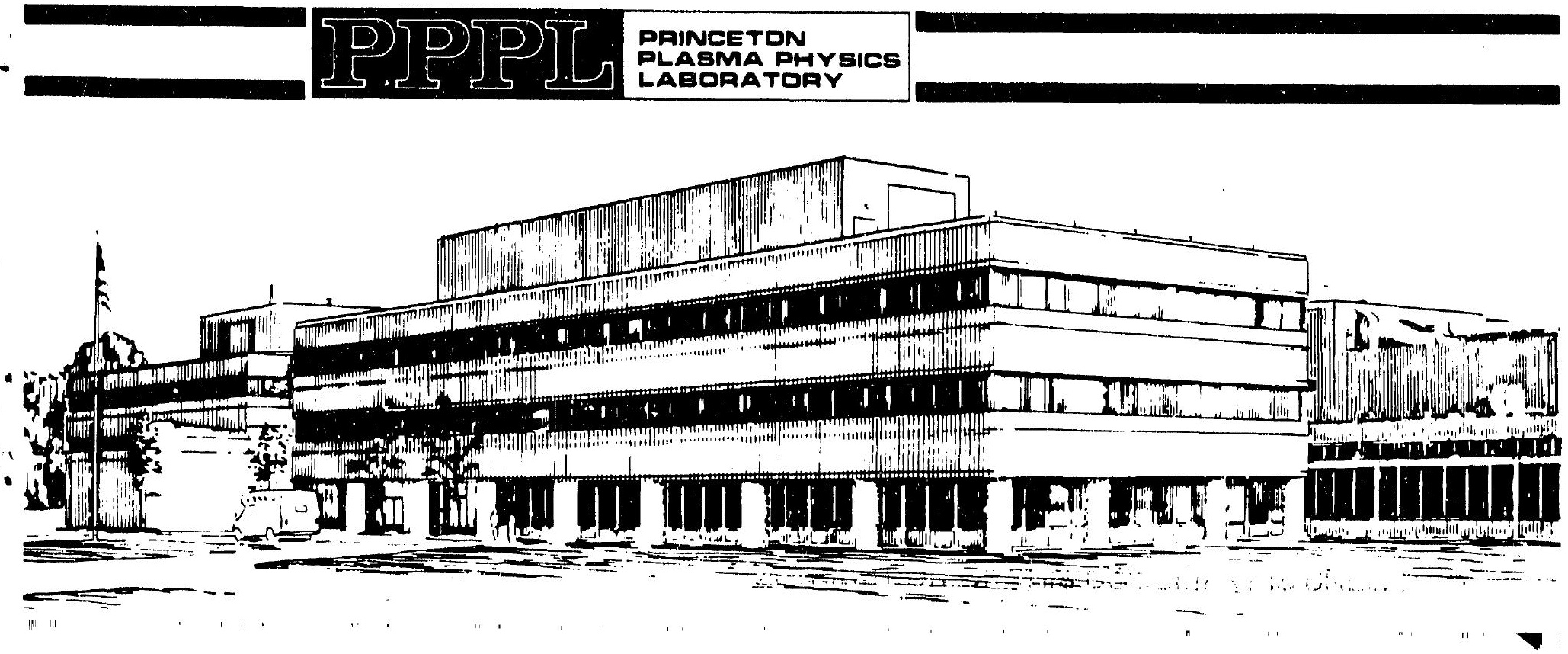


\section{NOTICE}

This report was prepared as an account of work sponsored by an agency of the United States Government. Neither the United States Government nor any agency thereof, nor any of their employees, makes any warranty, express or implied, or assumes any legal liability or responsibility for the accuracy, completeness, or usefulness of any information, apparatus, product, or process disclosed, or represents that its use would not infringe privately owned rights. Reference herein to any specific commercial produce, process, or service by trade name, trademark, manufacturer, or otherwise, does not necessarily constitute or imply its endorsement, recommendation, or favoring by the United States Government or any agency thereof. The views and opinions of authors expressed herein do not necessarily state or reflect those of the United States Government or any agency thereof.

\section{NOTICE}

This report has been reproduced directly from the best available copy.

Available to DOE and DOE contractors from the:

Office of Scientific and Technical Information P.O. Box 62

Oak Ridge, TN 37831 ;

Prices available from (615) 576-8401.

Available to the public from the:

National Technical Information Service

U.S. Di.partment of Commerce

5285 Port Royal Road

Springfield, Virginia 22161

$703-487-4650$ 


\title{
Calculation of Charged Fusion Product Distributions in Space, Energy, and Time
}

\author{
J. Schivell, D. A. Monticello, and S. J. Zweben \\ Princeton Plasma Physics Laboratory, Princeton University \\ Princeton, NJ 08543
}

PPPL- -2833

DE92 010005

\begin{abstract}
The equation for the radial diffusion and slowing down of fast ions in a plasma is solved by a finite-difference technique. The terms included are ion source, radial diffusion, electron and ion drag. From the ion density at the radial boundary, the loss flux is calculated and used to model the signals in a lost-ion diagnostic. The code is also used to model the density of $\alpha$-particles in future DT experiments. This information is used to predict the features to be seen by alpha diagnostics.
\end{abstract}

\section{MASTER}




\section{Introduction}

In order for a fusion plasma to be igaited, the charged fusion products must be confined in the plasma long enough to deliver a significant fraction of their kinetic energy to heating the plasma. Thus, it is important to study the confinement and losses of these charged fusion products (CFP). Recently, measurements of the losses of $\mathrm{MeV}$ protons and tritons from DD plasmas in TFTR have been reported [1]. That report relates the measurements to the CFP diffusion by means of an approximate diffusion calculation. The present paper describes a more detailed method of calculation, in which the slowing-down and radial diffusion terms are kept, and the differential equation is solved by a finite difference method. The results are compared with those from the approximate calculation, insofar as they relate to the experimental measurements in determining the diffusion coefficient for $\mathrm{MeV}$ inns. The finite difference calculation is also used to model the $\alpha-$ particle signals expected in future diagnostics: $\alpha$-Charge Exchange Recombination Spectroscopy ( $\alpha$-CHERS) and Collective Thomson ("Gyrotron") Scatiering.

To date, in TFTR, measurements relating to confinement of CFP have consisted of measurements of the lost ions, reported in ref. 1, and a number of measurements of other types, summarized in ref. 2. Here we address only the first of these existing measurements.

The lost-ion detector [1] accepts ions that reach the wall at a certain location with a certain range of pitch angle. The effect is that ions originally located in a certain zone of minor radius and pitch angle are detected. This is illustrated in Fig. 1. There is a second zone within which ions diffuse in radius until they reach the detector acceptance zone. Since we are considering fast ions, we can neglect pitch-angle scattering [3]. Under some 
conditions fast ions can be ejected by MHD activity in the plasma. The measurements considered here were for conditions without such MHD activity. The calculation of the lost-ion signals amounts to calculating the fast-ion density as a function of radius, energy, and time and then finding the flux crossing the passing-trapped particle boundary. This flux is added to that from first-orbit losses to model the signal. The $\alpha$-CHERS and Gyrotron Scattering diagnostics, in contrast, plan to measure the density of CFP in the interior of the plasma, including ions at significantly lower energy than presently detectable with the lost-ion detectors.

The full equation for the evolution of the CFP density in radius, energy, and time [3] contains terms for radial diffusion, electron and bulk-ion drag, pitch-angle scattering, energy diffusion, and E-field acceleration. In this work we neglect the last three effects. Pitch-angle scattering is neglected for two reasons: (1) for thu CFP's near birth energy, pitch-angle scattering is a negligible effect, and (2) even at much lower energies there is practically nothing that distorts the isotropic birth pitch-angle distribution. (Ions on the outer side of the plasma with large pitch angle are lost on bad orbits, but that anisotropy is neglected here.) Energy diffusion should not affect our results noticeably[3]. For loop voltage less than $1 \mathrm{~V}$ the E-field acceleration is less than the drag, even at the lowest energy considered, $100 \mathrm{keV}$.

The calculations in ref. 1, with which we are comparing, were done by grafting together a time-dependent solution neglecting energy variation and a steady-state sclution that gave the energy spectrum of the escaping fast-ion flux. 


\section{Method of Calculation}

The equation solved here contains terms for CFP ion source, radial diffusion, and the drag of electrons and bulk ions. In velocity space we have [3] for the density of CFP ions

$$
\frac{\partial}{\partial t} f(r, v, t)=\frac{1}{r} \frac{\partial}{\partial r}\left[r D \frac{\partial f}{\partial r}\right]+\frac{1}{\tau_{s e}} \frac{1}{v^{2}} \frac{\partial}{\partial v}\left[\left(v^{3}+v_{c}^{3}\right) f\right]+S(r, v, t)
$$

where $\mathrm{D}=$ the diffusion constant, $\tau_{\mathrm{se}}=$ the velocity slowing-down ( $e$-folding) time on electrons, $v_{c}$ is the "critical" velocity below which the bulk-ion Coulomb friction exceeds the electron Coulomb friction, and $\mathrm{S}$ is the source function of fast ions. Letting $\mathcal{F}(\mathrm{r}, \mathrm{E}, \mathrm{t})$ be the distribution function in terms of energy, and using $\mathcal{F}(\mathrm{E}) \mathrm{dE}=\mathrm{f}(\mathrm{v}) \mathrm{v}^{2} \mathrm{dv}$, we obtain

$$
\frac{\partial \mathcal{F}}{\partial \mathrm{t}}=\frac{1}{\mathrm{r}} \frac{\partial}{\partial \mathrm{r}}\left[\mathrm{rD} \frac{\partial \mathcal{F}}{\partial \mathrm{r}}\right]+\frac{1}{\tau_{\mathrm{sE}}} \frac{\partial}{\partial \mathrm{E}}\left[\left(\mathrm{E}+\mathrm{E}_{\mathrm{c}}^{3 / 2} \mathrm{E}^{-1 / 2}\right) \mathcal{F}\right]+\mathrm{S}_{\mathrm{E}}(\mathrm{r}, \mathrm{E}, \mathrm{t})
$$

where $E_{c}=1 / 2 \mathrm{mv}_{\mathrm{c}}^{2}, \tau_{\mathrm{sE}}=\tau_{\mathrm{se}} / 2$ is the slowing-down time in energy, and $\mathrm{S}_{\mathrm{E}}$ is the source function transformed to $\mathrm{E}$ space. In this report we find the finite-difference solution of Eq. (2).

The solution to Eq. (2) is expected to vary approximately as $\mathrm{E}^{-1}$ (for small diffusion), that is, more rapidly for small $\mathrm{E}$ [1]. In order to use constant step size in the numerical calculation it is advantageous to transform the equation from $\mathrm{E}$ to $\mathrm{x}=\ln \left(\mathrm{E} / \mathrm{E}_{\mathrm{b}}\right)$, where $\mathrm{E}_{\mathrm{b}}$ is a chosen lowest, or "bottom" energy. The transformed equation is

$$
\frac{\partial}{\partial \mathrm{t}} f(r, \mathrm{x}, \mathrm{t})=\frac{1}{\mathrm{r}} \frac{\partial}{\partial \mathrm{r}}\left[\mathrm{r} D \frac{\partial f}{\partial \mathrm{r}}\right]+\frac{1}{\tau_{\mathrm{sE}}} \frac{\partial}{\partial \mathrm{x}}\left[\left(1+\mathrm{e}^{\left.\left.3 \mathrm{x}_{\mathrm{c}} / 2 \mathrm{e}^{-3 \mathrm{x} / 2}\right) f\right]+S(\mathrm{r}, \mathrm{x}, \mathrm{t})}\right.\right.
$$


For finite differencing we take $\mathrm{i}$ as the time index, $\mathrm{j}$ as the radial index, and $\mathrm{k}$ as the index of $x$, with $x$ decreasing as $k$ increases. The donrain of $x_{k}$ extends from $x_{1}=\ln \left(E_{\max } / E_{b}\right)$ to $x_{K}=0$. First we calculate a half-step, with $f_{j, k}^{h}$ representing the value of $f_{j, k}^{i}$ after the half-step:

$$
\begin{aligned}
\cdot f_{j, k}^{h}=f_{j k}^{i} & +\frac{D(\Delta t / 2)}{(\Delta r)^{2} r_{j}}\left[r_{j+1 / 2}\left(f_{j+1, k}^{h}-f_{j, k}^{h}\right)-r_{j-1 / 2}\left(f_{j, k}^{h}-f_{j-1, k}^{h}\right)\right]+ \\
& \frac{(\Delta t / 2)}{\tau_{s E} \Delta x}\left(c_{k} f_{j, k}^{i}-c_{k-1} f_{j, k-1}^{i}\right)+\left(\frac{\Delta t}{2}\right) S_{j, k}^{i}
\end{aligned}
$$

where $c_{k}=1+e^{3 x_{d} / 2} e^{-3 x_{k} / 2}$. We have taken $D$ and $\tau_{s e}$ to be constants. The radial difference term is "implicit", that is, it uses the values of $f$ after the half-step [4]. The energy difference term uses "upwind" differencing. Next we use the $f_{j, k}^{h}$, the results of the half step, to take a partially implicit full step:

$$
\begin{gathered}
f_{j, k}^{i+1}=f_{j k}^{j}+\left(1-f_{i m p}\right) \frac{D \Delta t}{(\Delta r)^{2} r_{j}}\left[r_{j+1 / 2}\left(f_{j+1, k}^{i}-f_{j, k}^{i}\right)-r_{j-1 / 2}\left(f_{j, k}^{i}-f_{j-1, k}^{j}\right)\right]+ \\
f_{i m p} \frac{D \Delta t}{(\Delta r)^{2} r_{j}}\left[r_{j+1 / 2}\left(f_{j+1, k}^{i+1}-f_{j, k}^{i+1}\right)-r_{j-1 / 2}\left(f_{j, k}^{i+1}-f_{j-1, k}^{j+1}\right)\right]+ \\
\frac{\Delta t}{\tau_{s E} \Delta x}\left(c_{k} f^{h}{ }_{j, k}-c_{k-1} f_{j, k-1}^{h}\right)+\Delta t s_{j, k}^{i}
\end{gathered}
$$

where $\mathrm{f}_{\mathrm{imp}}$ is an adjustable parameter controlling the amount of implicitness in the solution. This is a generalization of the Crank-Nicholson method, discussed in ref. 4. The boundary conditions are as follows: $\partial \mathrm{f} / \partial \mathrm{r}=0$ at $\mathrm{r}=0$, which leads to $f_{1}=f_{2} ; f_{j}=0$ (where $\mathrm{J}$ is the maximum value of $\mathrm{j}$ ); no flow into the top energy bin, which leads to $f_{\mathrm{j}, 0}^{\mathrm{i}}=0$; and that those ions that flow down out of the bottom energy bin implicitly disappear. For each time 
step, at each value of $k$, there is a tridiagonal system of equations for the $f_{j, k}^{i+1}, j=1, J$, which is solved with the aid of the boundary conditions on $f(r)$. The outer boundary, $\mathrm{r}_{\mathrm{J}}$, is put at the radius to the fattest banana orbit (see Fig. 1) for the lost-ion calculations and at the plasma minor radius for the calculation for the other diagnostics.

The program embodying this algorithm has been named MeV-Ion Diffusion and Drag, or MIDD.

MIDD was tested with an arbitrarily chosen solution, which was substituted into Eq. (3) to determine an artificial source function. The chosen solution, which obeys the boundary conditions, is

$$
\begin{aligned}
f(r, x, t)= & P(r) A(t) R(x), \\
& \text { where } \\
P(r)= & {\left[1-(r / a)^{2}\right]^{m} } \\
A(t)= & 1-e^{-\lambda t} \\
R(x)= & \frac{x_{0}-x}{x+1}
\end{aligned}
$$

When applied to the artificial source function, MIDD produced values the same as those from Eq. (6), within very small errors. The errors are proportional to $(\Delta x)^{1}$ and to $(\Delta r)^{2}$, as expected. When MIDD was applied to a realistic source (see below), the solution converged as expected with decreasing $\Delta \mathrm{x}$ and $\Delta \mathrm{r}$. For the usual choices of $\Delta \mathrm{x}$ and $\Delta \mathrm{r}$ the stability limit on $\Delta t$ is determined by the energy drag terms rather than the diffusion term. We expect to need $\Delta t<\Delta x \tau_{s E} /\left(1+e^{3 x_{c} / 2}\right)$. With a typical value of $e^{3 x_{c} / 2}$ equal to 6 , we expect a limit of $1 / 7 \Delta x \tau_{\mathrm{sE}}$, and find by trial a limit of $1 / 6 \Delta \mathrm{x} \tau_{\mathrm{sE}}$. 
Figures 2 and 3 show the evolution of a pulse of fast ions, as calculated by MIDD. Here, and below, we used the following for the source function:

$$
\mathrm{S}_{\mathrm{E}}(\mathrm{r}, \mathrm{E})=\mathrm{S}_{0}\left(1-(\mathrm{r} / \mathrm{a})^{2}\right)^{\mathrm{m}} \mathrm{e}^{-\left(\mathrm{E}-\mathrm{E}_{0}\right)^{2} / 2 \sigma_{\mathrm{B}}^{2}}
$$

where $E_{0}$ is the birth energy in the rest frame. We used $m=8, \sigma_{E}=500 \mathrm{keV}$, and $\mathrm{D}=$ $0.1 \mathrm{~m}^{2} / \mathrm{s}$. The time dependence of the source for this test was (1) 0 . until $0.01 \mathrm{~s},(2)$ an exponential turn-on with a time constant of $0.01 \mathrm{~s}$, and (3) starting at $0.06 \mathrm{~s}$, an exponential fall with time constant $0.01 \mathrm{~s}$. The effect is a short pulse of the source. We see the development of the pulse of fast ions as it slows down and diffuses in radius. The exponential dependence of energy on time [1] produces a compression of the energy spectrum of the pulse as the ions slow down. Thus, the peak height increases. In Fig. 3 the E-axis is logarithmic, and the straight-line trajectory of the pulse shows the decay of the energy according to $E(t)=E_{0} \exp \left(-t / \tau_{s E}\right)$. At low energy the trajectory curves slightly downward, due to the effect of ion drag. Comparison of the pulse heights at the two different radii in Fig. 2 shows the effect of the radial diffusion, namely, that as the ions get older and slow down, there is a relatively greater density rise at the larger radii. At $0.06 \mathrm{~s}$ the density at $\mathrm{r}=0.62 \mathrm{~m}$ is only $1 / 30$ of that at $\mathrm{r}=0$, but at $0.46 \mathrm{~s}$ the fraction has risen to $1 / 4$.

The finite differencing produces dispersion in $\mathrm{x}$ [4]. We tested the size of the effect by observing the width of the slowed-down energy peak as a function of "The dispersion is a slowly varying function of $\Delta \mathbf{x}$. For typical parameters used below for calculating the signal in the lost-ion detector, we found that for an energy resolution of $\pm 350 \mathrm{keV}$ at $1000 \mathrm{keV}$, a $\Delta \mathrm{x}$ of 0.1 out of $4.0 \mathrm{i}$, fine enough. For the calculation of alpha densities for other diagnostics, the effect of numerical dispersion on the energy spectra was checked by reducing $\Delta \mathrm{x}$ by a factor of 8 (The $\mathrm{x}$ range is from 4.0 to 0 ., normally divided 
into 49 steps; for the check the number of steps was increased to 400 .). This caused changes in the spectra at the level of a few percent.

Table 1 lists the parameters normally used in the calculation.

\section{Comparisons with Approximate Calculation and Measurements}

MIDD was used to model the signals seen by the lost-ion detector, for protons and tritons and for a range of values of diffusion coefficient, D. The loss flux of diffusing ions was obtained from the gradient of density at the fattest-banana loss radius, $\mathrm{r}_{\mathrm{fb}}$. The flux of first-orbit loss to the detector was added. The energy-dependent response of the detector scintillator for protons and tritons (Fig. 4) was folded in.

For this case, the time dependence was (1) a rise time of $0.1 \mathrm{~s},(2)$ asymptotically constant until $1.0 \mathrm{~s}$, and (3) a fall time of $0.06 \mathrm{~s}$. The exponent of the parabola, $\mathrm{m}=8$, which was used for the radial dependence of the source, was obtained from observations with a collimated array of neutron detectors [1]. The source energy spectral spread, $\sigma_{\mathrm{E}}$, is determined primarily by the Doppler shift caused by the beam ion velocity. The spread in CFP energies has been investigated by several authors [5]. For DD reactions the spread is as large as $500 \mathrm{keV}$. For DT reactions it is even larger, $\sigma_{\mathrm{E}}=800 \mathrm{keV}$.

The first-orbit loss to the detector is related to the loss for the case of $D \rightarrow \infty$ [1]. In the latter case ions produced in the diffusion zone of Fig. 1 go immediatedly to $\mathrm{r}_{\mathrm{fb}}$ and then go out to the detector. The ratio of diffusion loss with $\mathrm{D} \rightarrow \infty$ to first-orbit loss is called $\Omega$ and is $q$ function of the source radial distribution. It is calculated in ref. 1 to be 2.5 for this case. The first-orbit loss, then, is calculated by taking a large value of $D(D=10)$ and 
using MIDD to calculate loss flux, as a function of energy and time [6]. This flux is then divided by $\Omega$.

For any value of $D$ for which one wishes to calculate, the loss flux with that $D$ is added to the first-orbit loss and integrated with the scintillator response. The process is done for protons and tritons and the results added to give the calculated signal.

One measurement of $D$ in ref. 1 is the effect of plasma current on the lost-ion flux. If $D=0$, the flux would be reduced by a factor of 5 as current increased from $0.6 \mathrm{MA}$ to 1.8 MA. At a high current like 1.8 MA, the flux, or signal, is sensitive to the value of D. The first application of MIDD is to calculate the flux, under this condition, as a function of $\mathrm{D}$ and compare it with that calculated with the ref. 1 approximate calculation (AC). Figure 5 shows the results. Plotted is the total signal for protons plus tritons, with scintillator response folded in. The determination in ref. 1 --that $\mathrm{D}<0.1 \mathrm{~m}^{2} / \mathrm{s}-$-is unaltered by the more accurate calculation with MIDD. In fact, MIDD calculates a somewhat higher flux for, e.g., $\mathrm{D}=0.1$, strengthening the conclusion slightly.

The decay of the calculated signal after neutral beam turn-off was compared with the decay in the AC and with the decay of the source. These quantities are plotted in Fig. 6. Some or all of the difference between the result of the finite-difference calculation, MIDD, and that of the AC is due to the use of a realistic source energy width $\left(\sigma_{E}=500 \mathrm{keV}\right)$ in the former. This was tested by substituting $\sigma_{\mathrm{E}}=100 \mathrm{keV}$ in MIDD; that produced the line for "narrow source" in the figure.

For comparing with the measurements, we plot the signal at each time divided by the neutron flux at that time. The result would be constant in time in either the case of $D=0$ or the case of $D=\infty$. The results are shown in Fig. 7, where measurements and calculations 
are normalized to their values at the end of the neutral beam injection. The curves calculated with MIDD are systematically higher than those done with the AC. Specifically, at $1.16 \mathrm{~s}$ the curve for $\mathrm{D}=0.03$ is $30 \%$ higher than its counterpart calculated with the $\mathrm{AC}$; the curve for $D=0.1$ is $40 \%$ higher, and the curve for $D=0.3$ is $60 \%$ higher. Thus the conclusion in ref. 1 , that $D$ is less than $0.1 \mathrm{~m}^{2} / \mathrm{s}$, is again strengthened by comparing with the results of MIDD.

We also compare the MIDD result for the apparent mean gyroradius of the escaping ions with measured values, as a function of time. This is shown in Fig. 8. In this case the MIDD curves soften the conclusion slightly but not enough to alter it substantially.

The conclusion is that the finite-difference solution of the time-dependent equation, Eq. (2), shows that the approximate calculation was adequate for analyzing the measurements made with the lost-ion detector. The determination of $D<0.1 \mathrm{~m}^{2} / \mathrm{s}$ stands.

\section{Modeling Signals from Other Alpha Diagnostics}

The plans for TFTR include new diagnostics for measuring the density of $\alpha$-particles and possibly their energy spectra. Two of these diagnostics under development are $\alpha$ Charge Exchange Recombination Spectroscopy and Collective Thomson ("Gyrotron") Scattering. The diffusion coefficient, $\mathrm{D}$, and slowing-down time, $\tau_{\mathrm{sE}}$, have strong effects on the time behavior, radial profile, and energy spectrum of the $\alpha$-particles. This could lead to good measurements of $\mathrm{D}$ and $\tau$. 
The modeling required from MIDD is somewhat different for these diagnostics than for lost-ion detectors. First, the new diagnostics will measure the density inside the plasma, rather than the flux across a loss radius. Second, the energy range of ions that they will be able to see extends much lower than the range detected by the lost-ion detectors. The $\alpha$-CHERS will be looking in the range from thermal energy to $500 \mathrm{keV}$, rather than the $E>\sim 1000 \mathrm{keV}$ to which the lost-ion detectors are presently sensitive. The Gyrotron Scattering may cover both ranges. Third, in this calculation we put the boundary radius, $a_{b}$, at the plasma minor radius, rather than at the radius of the fattest banana as above [7]. The smallest differences are those due to the ion species being the $\alpha$-particle. This is due to the facts that the gyroradius of the alpha from DT fusion is nearly the same as that of the proton or triton from DD fusion, and that the slowing-down time, $\tau_{\mathrm{sE}}$, is $0.225 \mathrm{~s}$, not very different from the $0.2 \mathrm{~s}$ for the proton. The magnitude of the source rate is chosen to correspond to the ac ual reaction rate expected for a high-yield DT plasma in TFTR [8]. The radial shape of the source is taken to be a parabola to the eighth power, which models the shape in ref. 8 closely. (Note that the time deperidence of the source rate is slightly different from that used in the previous sections.)

The calculated densities, as shown in Figs. 9-11, display a number of useful features. First, the signals seen by these diagnostics will be significantly delayed with respect to the beam heating and alpha birth time. This is shown in Fig. 9, in which the alpha densities at near-birth energy and at 100, 200, and $400 \mathrm{keV}$ are plotted as functions of time. The signals seen at these energies are delayed approximately $0.4 \mathrm{~s}$ from the alpha birth time [9]. That means that, for the (typical) beam heating time of $0.9 \mathrm{~s}$, the signals have not quite reached their maxima when the beams are shut off. (The delay seen here is consistent with the $\tau_{\mathrm{SE}}$ value of $0.225 \mathrm{~s}$ and two $e$-folding times in energy.) 
Since diagnostics that look at low-energy alphas are looking at old alphas, they are quite sensitive to $\mathrm{D}$. Figure 10 shows the radial profiles calculated for $\mathrm{D}=0 ., 0.1$, and $0.5 \mathrm{~m}^{2} / \mathrm{s}$, where the densities have been integrated from 100 to $400 \mathrm{keV}$ to simulate the detection range of $\alpha$-CHERS. The radial profiles are quite distinct, and the densities in the center and in the region $0.5<\mathrm{r}<0.6 \mathrm{~m}$ differ by large factors among the cases. Even though a diffusion coefficient of $\mathrm{D}=0.1 \mathrm{~m}^{2} / \mathrm{s}$ is usually not considered large, it dramatically affects the density profile of low-energy alphas. (A note of caution: the radial profile is also affected by the alpha birth profile, the slowing-down time, and the electron temperature, through its effect on the critical energy for ion drag.)

The energy spectrum is also sensitive to $D$. Figure 11 shows the energy spectra at the plasma center, calculated for $D=0 ., 0.1$, and $c 5 \mathrm{~m}^{2} / \mathrm{s}$. It would not be hard to obtain a good determination of $\mathrm{D}$ from an approximate measurement of the spectrum.

\section{Energy Spectrum: Comparisons with Other Models}

Knowledge of the energy spectra of charged fusion products is necessary for theoretical calculations of instabilities, as well as for experimental purposes. The simplest model of the energy spectrum is the steady-state spectrum neglecting diffusive loss. That is

the simple $E^{-1}$ spectrum. A typical steady-state solution including diffusive loss gives [1] a spectrum that varies as $E^{\eta-1}$, where $\eta=5.6 \Gamma \tau_{\mathrm{sE}} / \mathrm{a}_{\mathrm{b}}^{2}$, and $\mathrm{a}_{\mathrm{b}}$ is the boundary radius. With MIDD we can calculate the spectrum using a realistic source radial profile and source energy spread and time dependence. In Fig. 12 we have plotted comparisons, at three typical times, of the MIDD-calculated spectra with a spectrum that varies as $E^{\eta-1}$. The differences are evident and should be useful for stability estimates. 


\section{Conclusions}

W have developed a detailed calculation, combining radial diffusion and drag, of the charged fusion product density in space, energy, and time. This calculation allows for an arbitrary source term. The crde, MIDD, has been used to check the approximate calculations which were used in analyzing lost-ion measurements of $\mathrm{MeV}$ ions. No change in the conclusion was found necessary. The energy spectra from the detailed calculation were compared with an analytic-formula spectr $\mathrm{m}$ from a steady-state solution. During equilibrium in the plasma conditions, the agreement is fairly good, but the steady-state formula becomes inapplicable when the conditions are changing. We have also applied MIDD to calculating the alpha densities to be measured by new alpha diagnostics. The results showed strong features to look for in the signals of these diagnostics. MIDD will, of course, be useful in the future for analysis of these and other $\alpha$-particle measurements on DT plasma.s.

\section{Acknowledgments}

We wish to thank Drs. D. L. Jassby, B. C. Stratton, and H. K. Park for helpful discussions. This work was supported by the U. S. Department of Energy under contract No. DE-AC02-76-CHO-3073. 


\begin{tabular}{|c|c|c|c|c|}
\hline \multicolumn{5}{|c|}{ Table 1: Parameters used in the Calculation } \\
\hline & & proton & triton & alpha \\
\hline birth energy, $E_{0}$ & $\mathrm{keV}$ & 3000 & 1000 & 3500 \\
\hline critical energy ${ }^{1}, \mathrm{E}_{\mathrm{c}}$ & $\mathrm{keV}$ & 100 & 300. & 330 \\
\hline top calc. energy, $E_{\max }$ & $\mathrm{keV}$ & 4500 & $200 C$ & 5100 \\
\hline bottom calc. energy, $E_{b}$ & $\mathrm{keV}$ & 1104 & 368 & 100 \\
\hline$\sigma_{E}$ & $\mathrm{keV}$ & 500 & 500 & 800 \\
\hline source amplitude, $\mathrm{S}_{0}$ & & 1. & $1.45 \times 10^{14}$ & $1.45 \times 10^{14}$ \\
\hline exp. of parabola, $m$ & & 8 & 8 & 8 \\
\hline$\tau_{\mathrm{sE}}$ & s & 0.2 & 0.6 & 0.225 \\
\hline plasma radius, a & $\mathrm{m}$ & 0.95 & 0.95 & 0.8 \\
\hline boundary radius, $a_{b}$ & $\mathrm{~m}$ & 0.494 & 0.494 & 0.8 \\
\hline major radius, $\mathrm{R}_{\mathrm{maj}}$ & $\mathrm{m}$ & 2.6 & 2.6 & 2.45 \\
\hline$\Delta \mathrm{r}$ & $\mathrm{m}$ & 0.025 & 0.025 & 0.05 \\
\hline$x_{1}=\ln \left(E_{\max } / E_{b}\right)$ & & 4.076 & 1.693 & 3.932 \\
\hline $\mathrm{x}_{\mathrm{K}}$ & & 0. & 0. & 0. \\
\hline$\Delta \mathrm{x}$ & & 0.027 & 0.017 & 0.080 \\
\hline$\Delta \mathrm{t}$ & $\mathrm{s}$ & $8.3 \times 10^{-4}$ & $2.5 \times 10^{-3}$ & $3.0 \times 10^{-3}$ \\
\hline
\end{tabular}




\section{References}

[1] Zweben, S. J., et al., PPPL-2770, accepted by Nucl. Fusion (1991).

[2] Hawryluk, R. J., et al., Proc. 18th Conference of the European Physical Society Plasma Physics Division, Berlin, Germany, 3-7 June 1991.

[3] Jassby, D. L., Nucl. Fusion 17, 309 (1977).

[4] Pottei, David, Computational Physics (Wiley, New York, 1973).

[5] Lehner, G., Z. Physik 232, 174 (1970), Towner, H. H., Princeton Plasma Physics Laboratory Tech. Memo TFTR-1 (1976) and private comm., and Sadler, G., IAEA Tech. Comm. Meeting on $\alpha$-Particles in Fusion Research, Aspenas, Goteborg, Sweden, 10-14 June, 1991.

[6] It would be more intellectually pleasing to calculate it by integrating the source function over $0<\mathrm{r}<\mathrm{r}_{\mathrm{fb}}$.

[7] In the solution of the difference equation we set $r_{J}=a_{b}$.

[8] Budny, R., et al., "Simulations of DT Experiments in TFTR", to be published in Nucl. Fusion. 
[9] Similar time delays in triton burn-up in deuterium plasmas have been reported in Conroy, S., et al., Nucl. Fusion 28, 2127 (1988), Strachan, J. D., et al.,. Plasma Physics and Controlled Nuclear Fusion Research (IAEA, Vienna) I, 257 (1989), and Jarvis, C. N., et al., Proc. 18th Conference of the European Physical Society Plasma Physics Division, Berlin, Germany, 3-7 June 1991. In the case of DD tritons the maximum reactivity is at $180 \mathrm{keV}$. 


\section{Eigure Captions}

Fig. 1. Schematic diagram of guiding center orbits of fusion protons and tritions for a 1.8 MA plasma in TFTR. Vertical scale is normalized magnetic moment, and horizontal is midplane ninor radius crossing point. Shown are the region of first-orbit losses to the lost-ion detector and the region of ions that diffuse to that region.

Fig. 2. Evolution of a pulse of protons. Boundary at $\mathrm{r}=0.95 \mathrm{~m}, \mathrm{D}=0.1 \mathrm{~m}^{2} / \mathrm{s}$. (a) Spectra at $r=0$., (b) spectra at $r=0.62 \mathrm{~m}$.

Fig. 3. Evolution of a pulse of protons. Proton density at $r=0$. as a function of energy and time. Note logarithmic energy scale.

Fig. 4. Detector sensitivity vs. ion energy for the CFP protons and tritons observed in ref. 1. The energy plotted is relative to the birth energy, $3.0 \mathrm{MeV}$ for protons and $1.0 \mathrm{MeV}$ for tritons.

Fig. 5. Lost-ion flux as a function of assumed diffusion coefficient, D, calculated with MIDD and with the approximate method of ref. 1. Scintillator response has been folded in.

Fig. 6. Calculated lost-ion signals after turn-off of neutral beams, normalized to the signals just before turn-off. The source decay time is $0.06 \mathrm{~s}$. "narrow" is for $\sigma_{\mathrm{E}}=$ $100 \mathrm{keV}$. 
Fig. 7. Lost-ion signals divided by neutron flux, normalized to values just before beam turn-off. The calculated values are from MIDD, using the full-width source energy spectrum, $\sigma_{\mathrm{E}}=500 \mathrm{keV}$. Psints with error bars are the measured data.

Fig. 8. Measured and calculated gyroradius as a function of time. Conditions the same as in Fig. 7.

Fig. 9. Alpha density $v s$. time at source and low energies, at $r=0$. Calculation done for $D=0.1 \mathrm{~m}^{2} / \mathrm{s}$. In the case $D=0$. the plot is quite similar, except that the peak densities at the low energies are in the range 2.-2.5 $\times 10^{14}$.

Fig. 10. Radial profiles of low-energy alpha population for three values of $D\left(\mathrm{~m}^{2} / \mathrm{s}\right)$. The time is at $0.9 \mathrm{~s}$, the end of the beam-on interval. The alpha populations have been integrated from 100 to $400 \mathrm{keV}$.

Fig. 11. Energy spectra at $r=0$. for three values of $D\left(\mathrm{~m}^{2} / \mathrm{s}\right)$ at $0.9 \mathrm{~s}$.

Fig. 12. Normalized energy spectra at $r=0$. calculated with the steady-state form $E^{\eta-1}$ (see text) and with MIDD. The quantity plotted is $E \mathcal{F}(E)$, the dashed line is from the steady-state formula, and the solid line is from MIDD. This calculation was done for alphas with $D=0.1 \mathrm{~m}^{2} / \mathrm{s}, \tau_{\mathrm{sE}}=0.225 \mathrm{~s}$, and $\mathrm{a}_{\mathrm{b}}=0.8 \mathrm{~m}$, giving $\eta=0.2$. The source energy spectrum had $\sigma_{\mathrm{E}}=800 \mathrm{keV}$, and the time profile of alpha production was the same as in Fig. 9. Spectra are (a) at $0.3 \mathrm{~s}$, (b) at $0.9 \mathrm{~s}$, and (c) at $1.1 \mathrm{~s}$. 


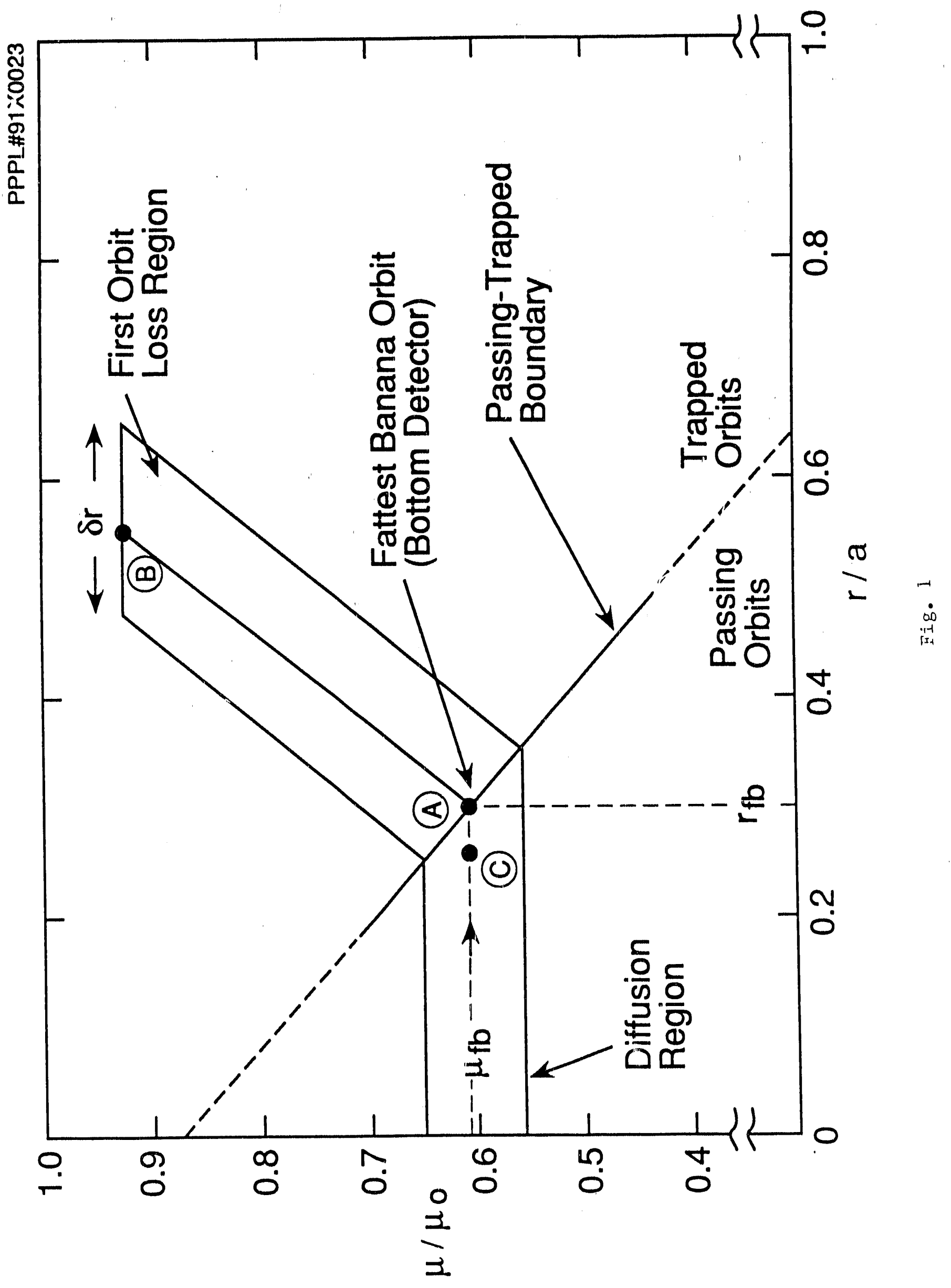



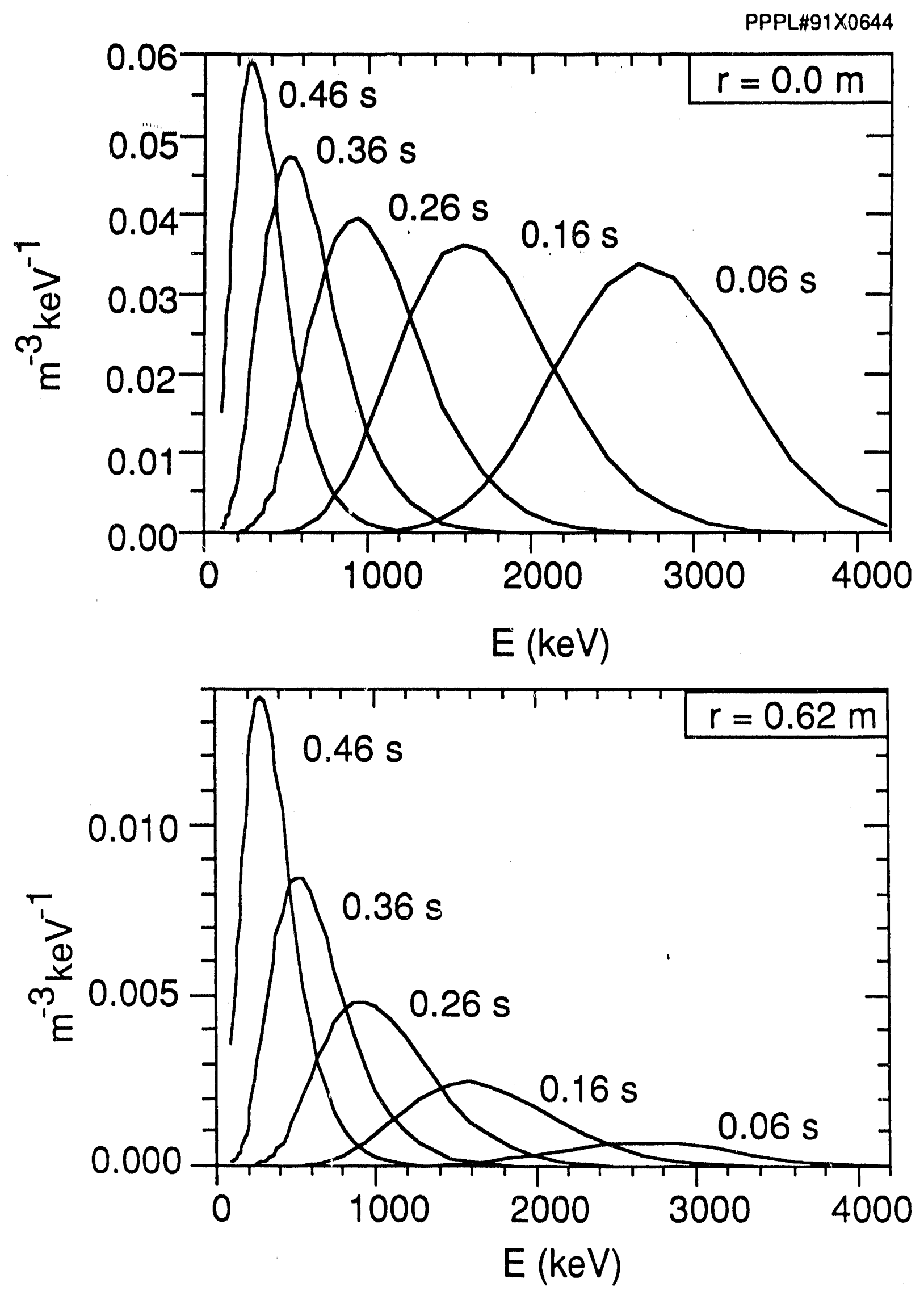


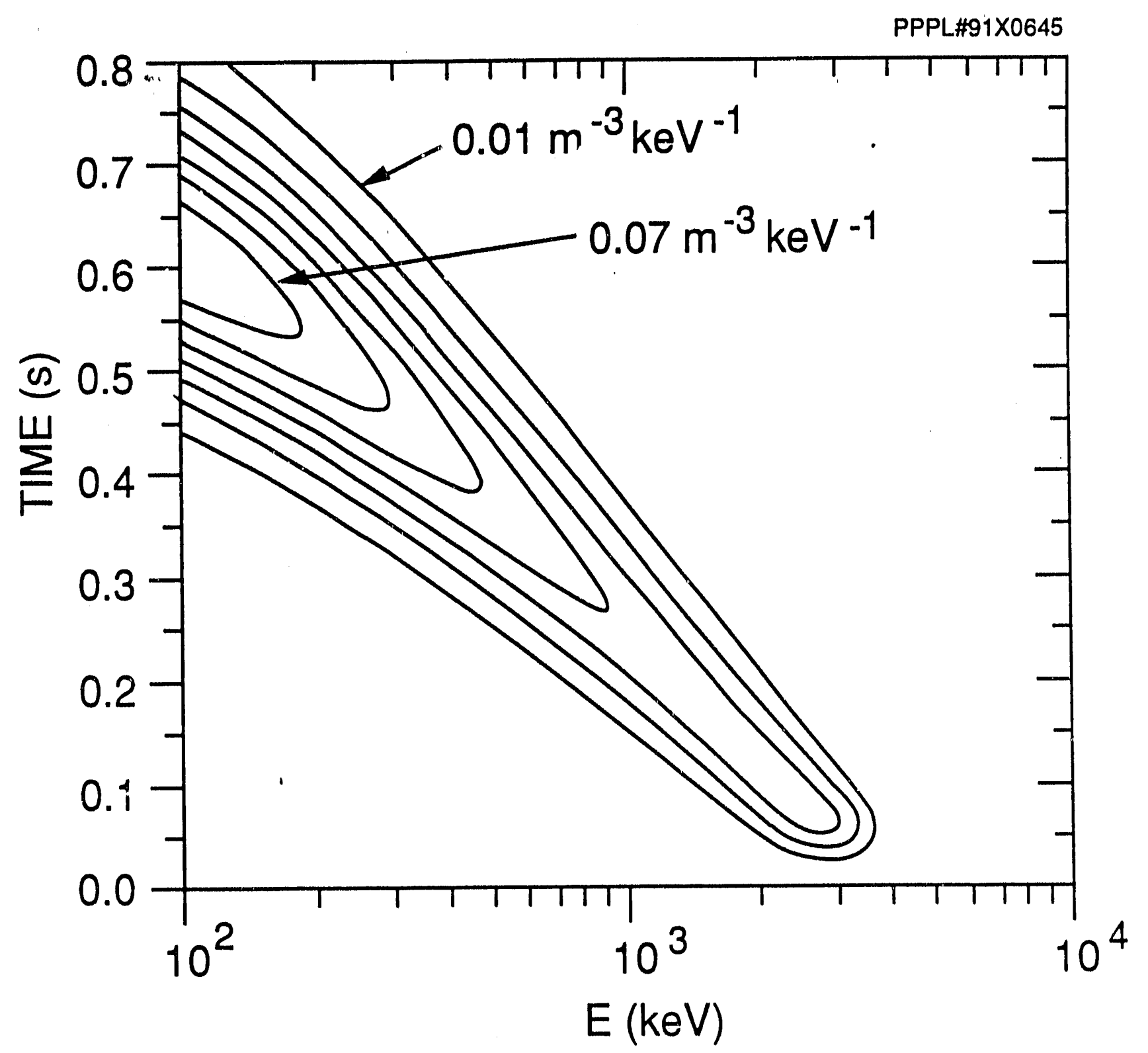

Fig. 3 


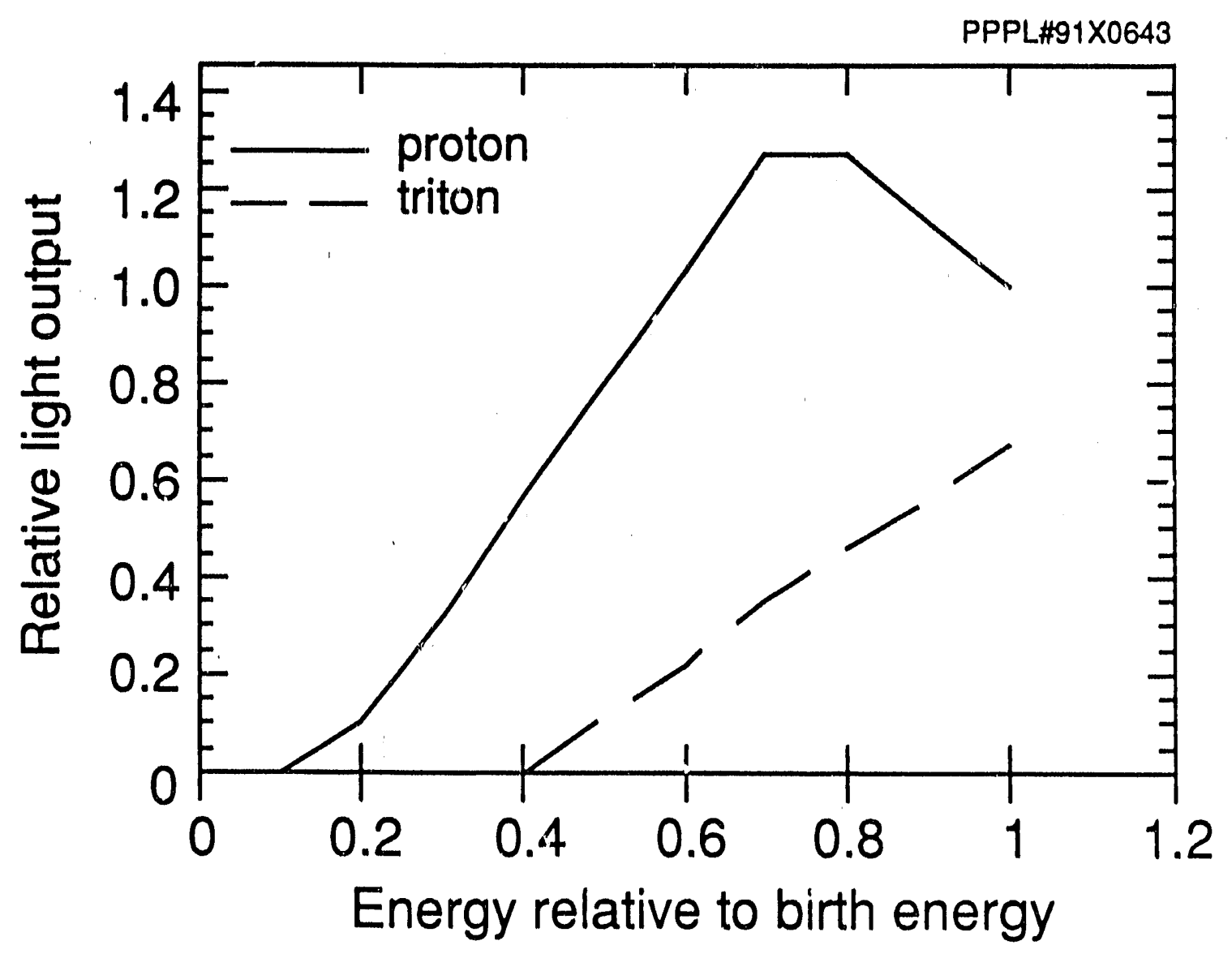

Fig. 4 


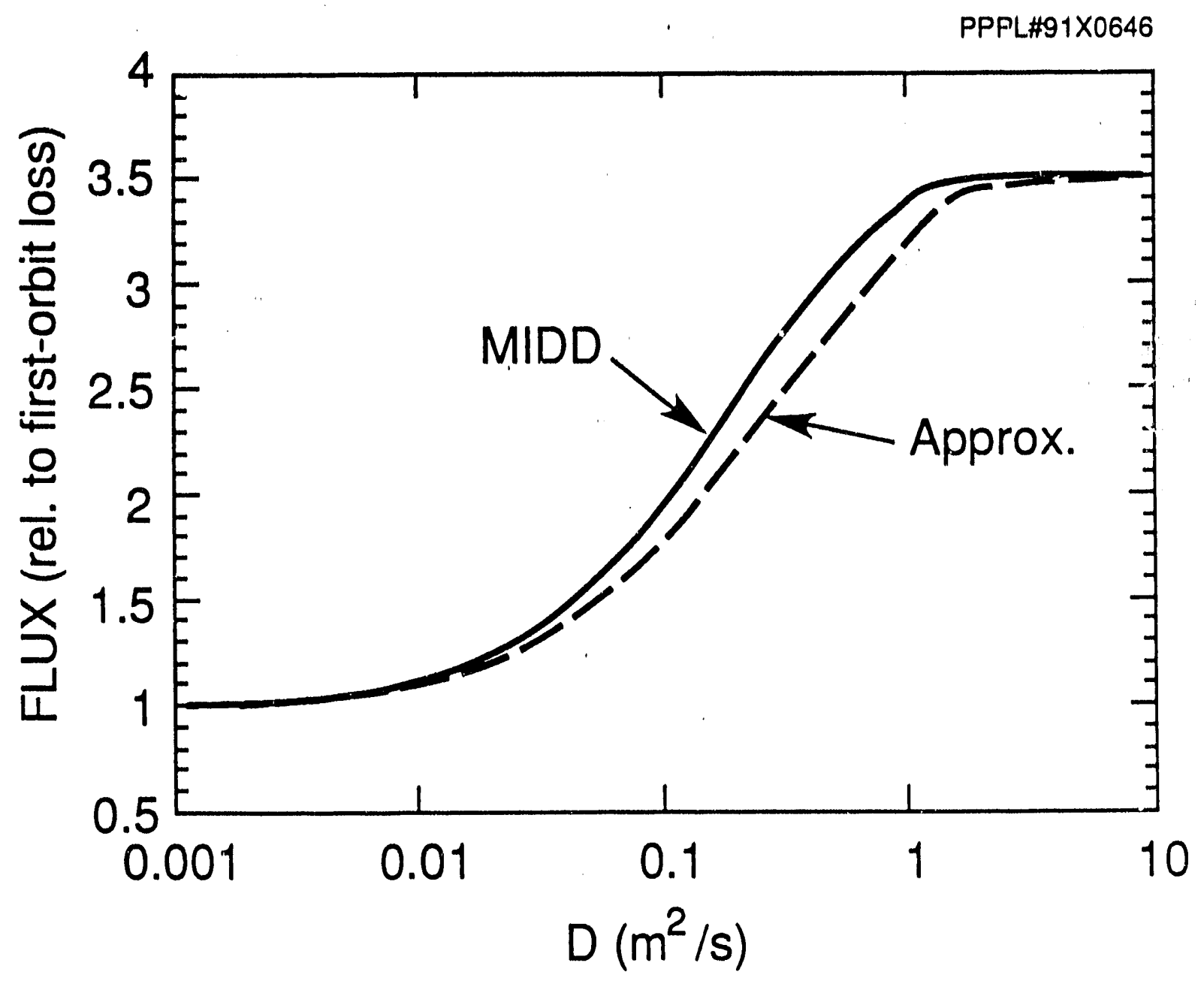

Fig. 5 


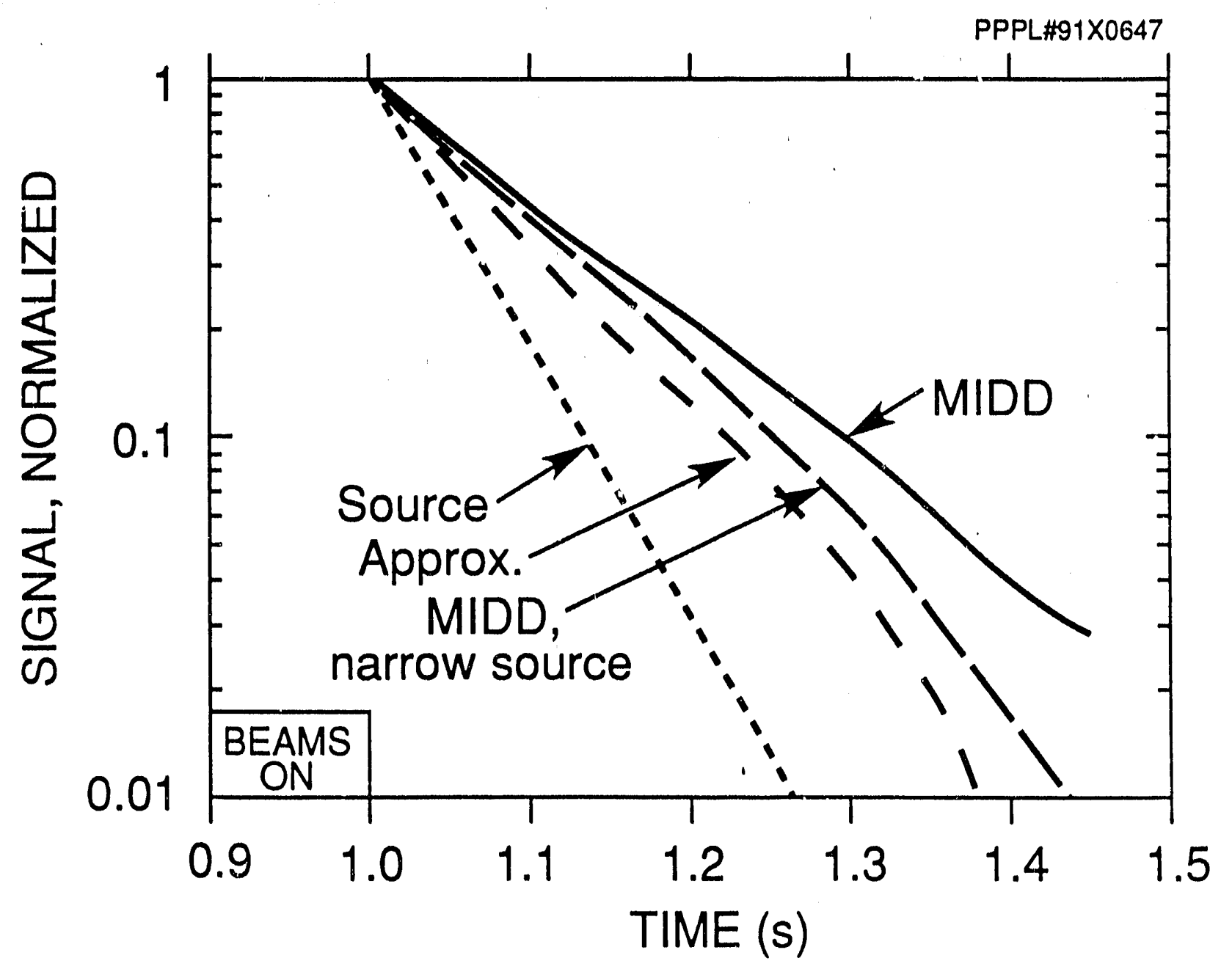

FIg. 6 


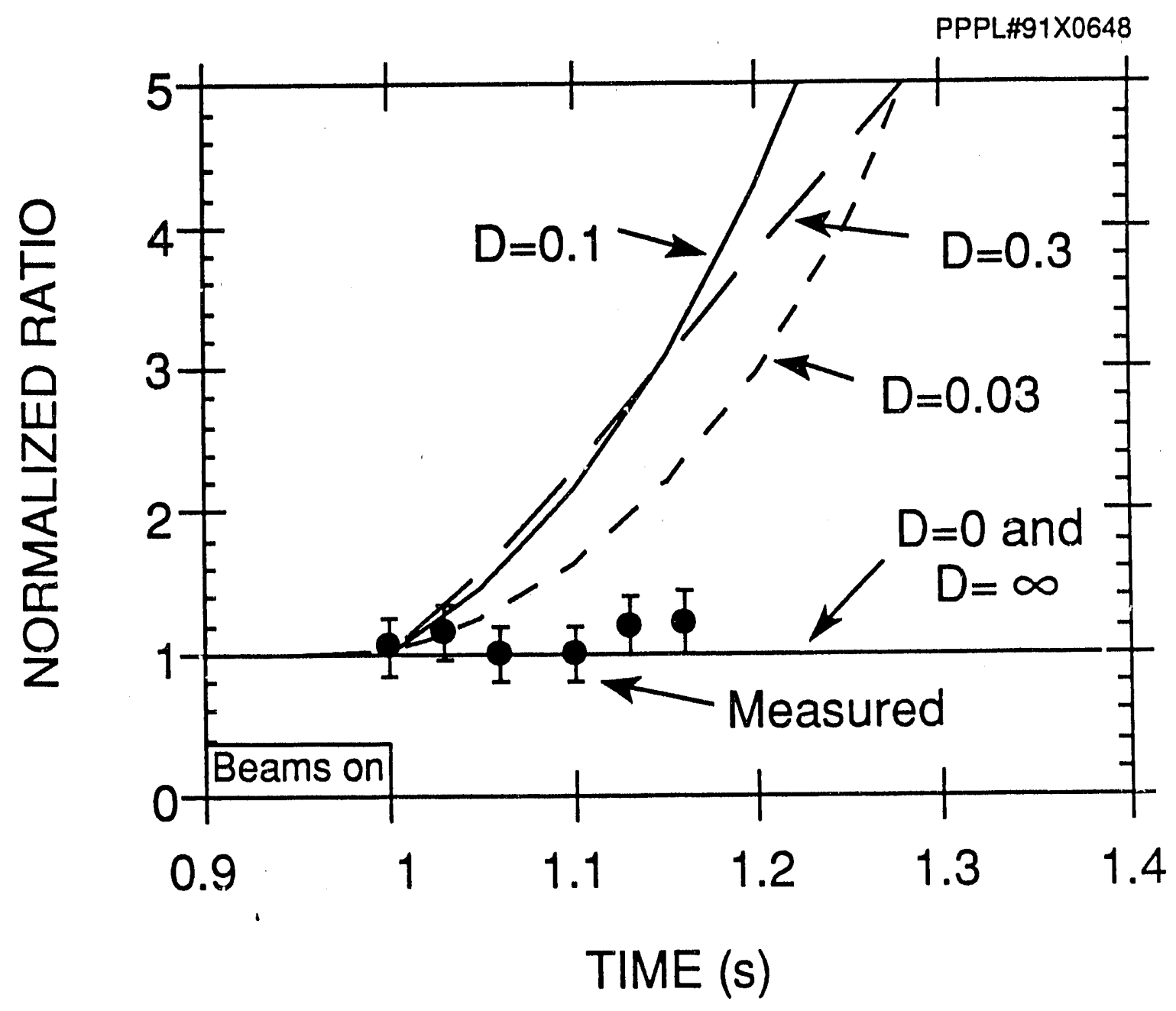

Fig. 7 


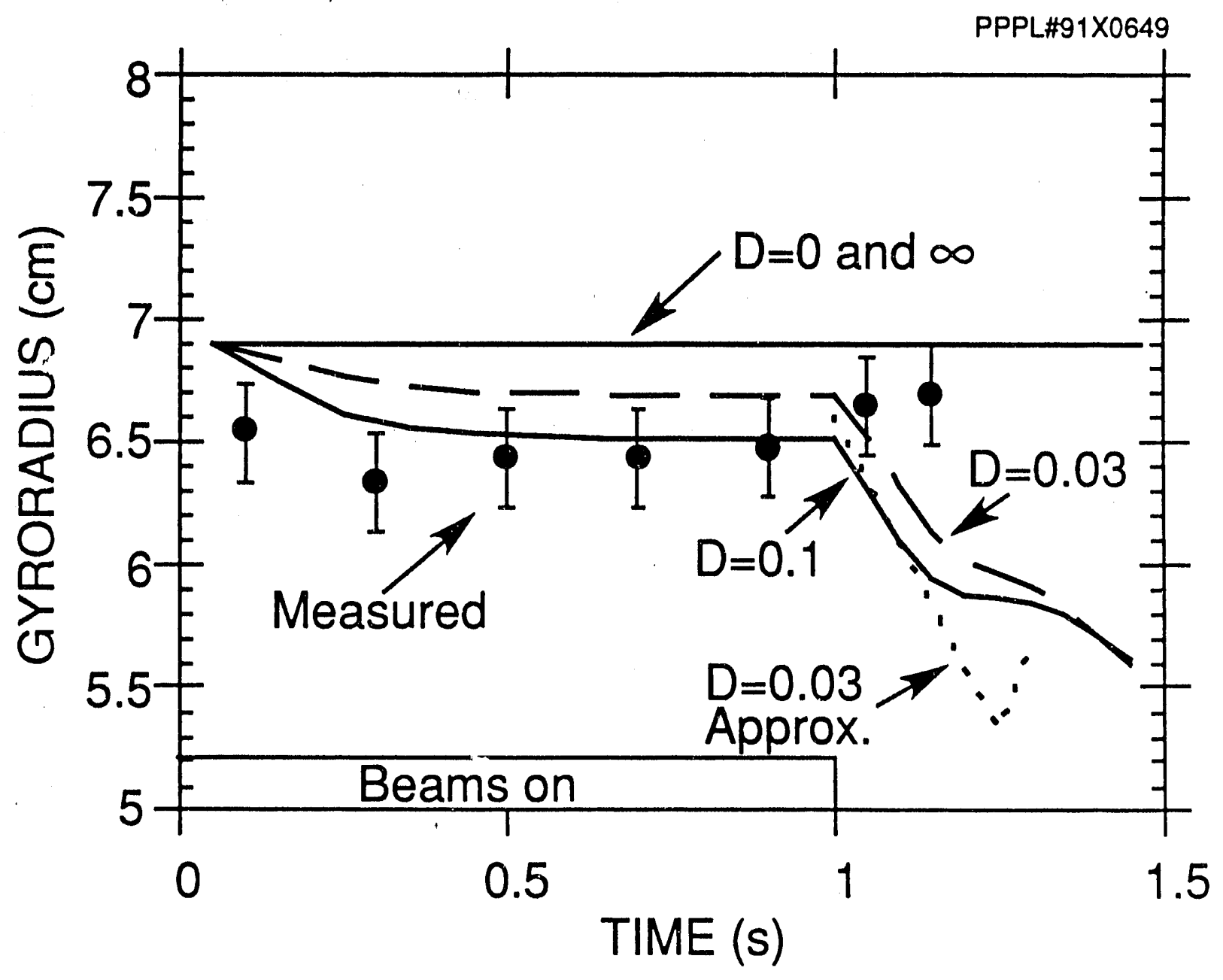

Fig. 8 


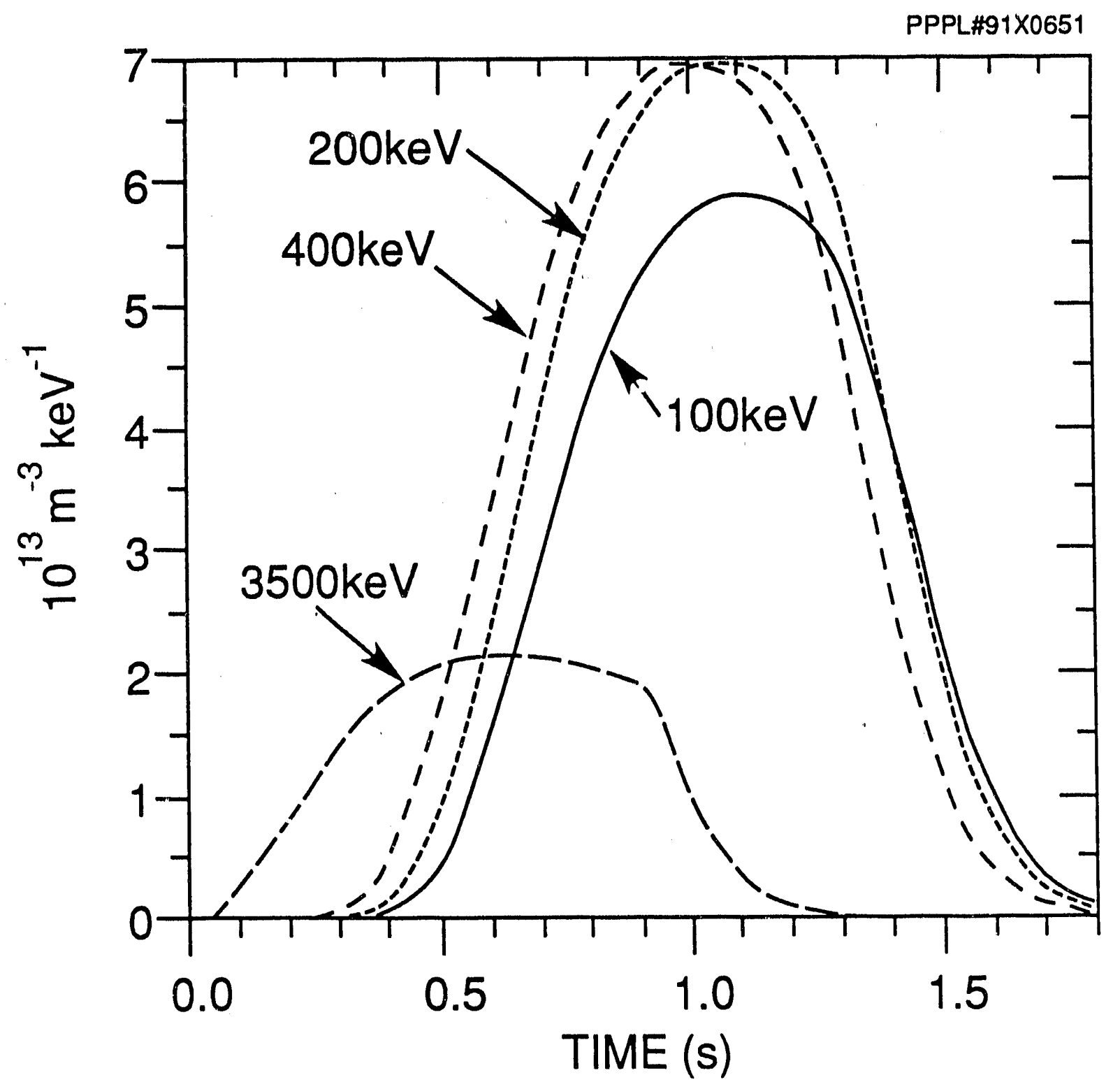




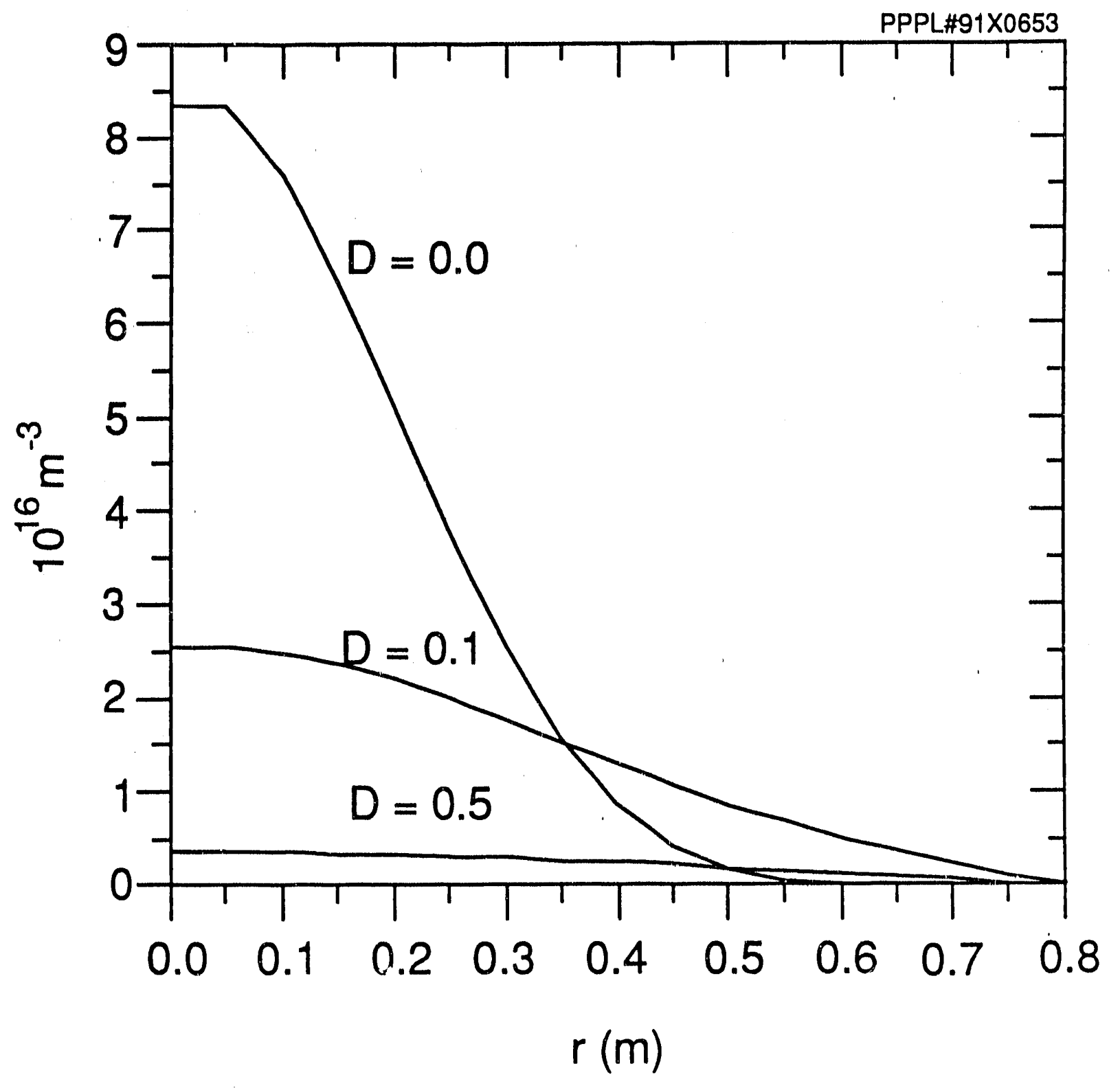

Fig. 10 


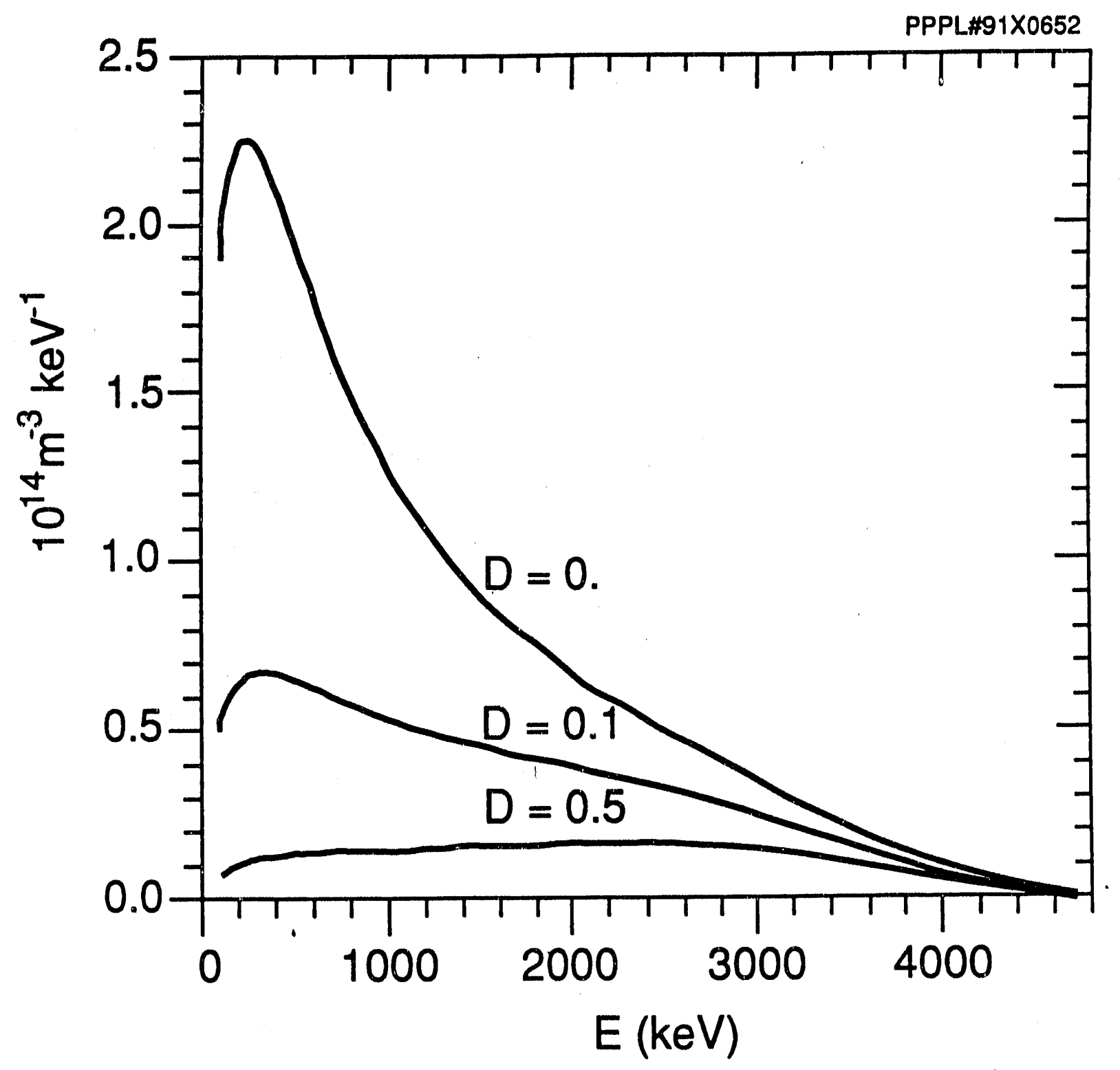

Fig. 11 


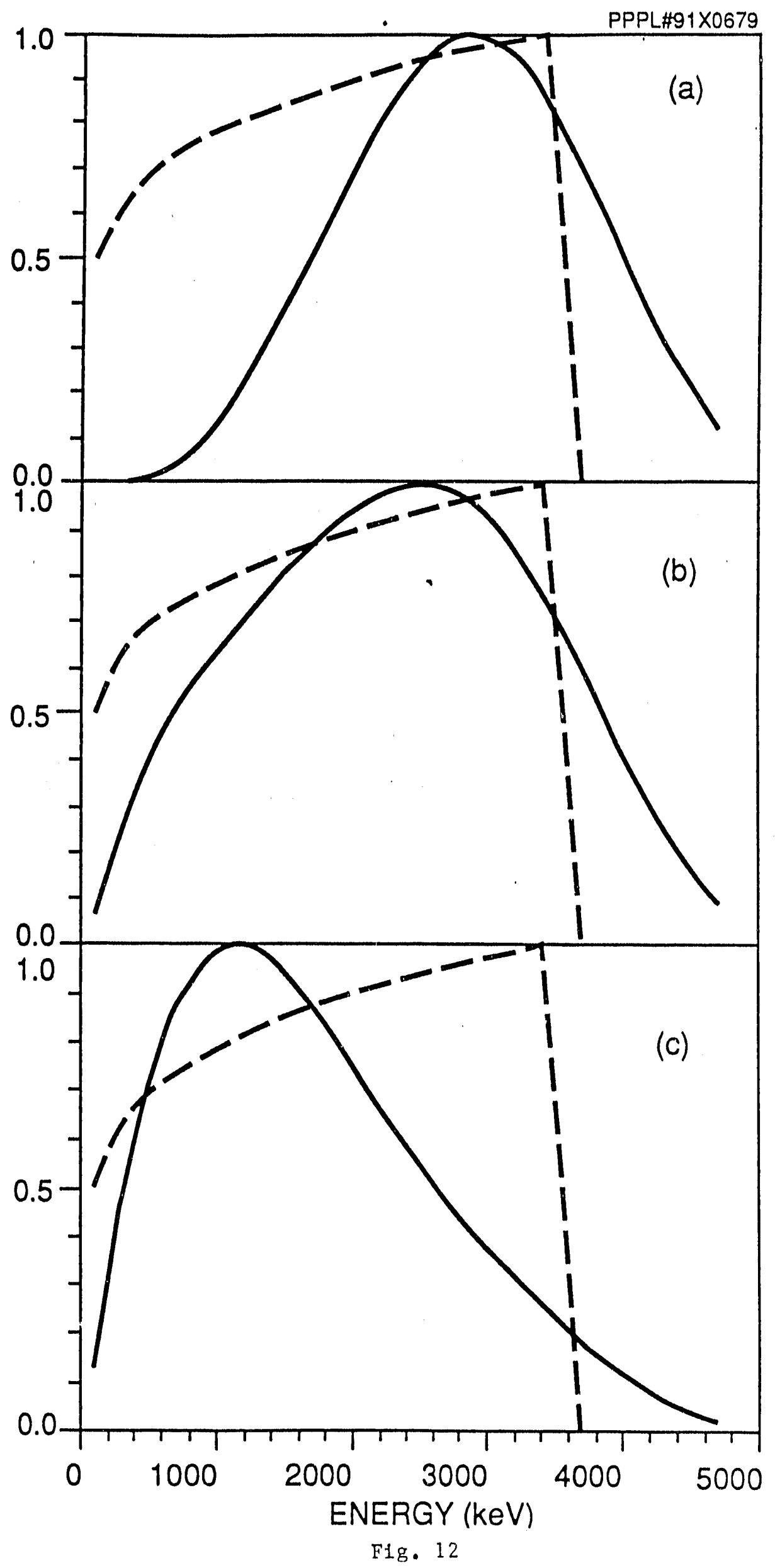


Dr. F. Peoloni, Univ. of Wollongong, AUSTRALIA

Prof. M.H. Brennan, Univ, of Sydney, AUSTRALIA

Plasma Research Lab., Australian Nat. Univ., AUSTRALIA

Prof. I.R. Jones, Flinders Univ, AUSTRALIA

Prof. F. Cap, Inst. for Theoretical Physics, AUSTRIA

Prof. M. Heindler, Instiut for Theoretische Physik, AUSTAIA

Prot. M. Goossens, Astronomisch Instituut, BELGIUM

Ecole Roydo Militeire, Lab. de Phy. Plaemac, BELGIUM

Commission-Europeen, DG. XII-Fusion Prog., BELGIUM

Prof. R. Boucique, Rijksuniveriloit Gont, BELGIUM

Dr. P.H. Sakanaka, Instituto Fiaica, BRAZIL

Instituto Nacionel Do Poequisas Espadair-INPE, BRUZIL

Documents Office, Alomic Energy of Ceneda Lid., CANADA

Dr. M.P. Bechynski, MPB Technologies, Inc., CANADA

Dr. H.M. Skarsgard, Univ. of Sackatchowen, CANADA

Prof. J. Toictmann, Univ, of Montreal, CANADA

Prof. S.R. Sreenivasen, Univ. of Calgary, CANADA

Prof. T.W. Johnston, INRS-Energio, CANADA

Dr. R. Bolton, Centre canadien de fusion magnétique, CANADA

Dr. C.R. James, Univ. of Alborta, CANADA

Dr. P. Lukác, Komonského Univorszita, CZECHO-SLOVAKIA

The Librarian, Culham Leboratory, ENGLAND

Library, A61, Rutherford Applation Laboratory, ENGLAND

Mrs. S.A. Hutchinson, JET Library, ENGLAND

Dr. S.C. Sharma, Univ. of South Pacific, FIJI ISLANDS

P. Mahonen, Univ. of Helsinki, FINLAND

Prof. M.N. Bussac, Ecole Polytechnique, FRANCE

C. Mourtet, Lab. do Physique dos Milioux lonisés, FRANCE

J. Radet, CEN/CADARACHE - Bat 506, FRANCE

Prof. E. Economou, Univ. of Croto, GREECE

Ms. C. Rinni, Univ. of loannina, GREECE

Dr. T. Mual, Acadomy Bibliographic Ser., HONG KONG

Preprint Library, Hungarian Acadomy of Sci., HUNGAAY

Dr. B. DasGupta, Saha Inst. of Nuclear Physics, INDIA

Dr. P. Kaw, Inst. for Plasma Research, INDIA

Dr. P. Rosenau, Israel inst. of Technology, ISPAEL

Librarian, Intomational Conter for Thoo Physics, ITALY

Miss C. De Palo, Associazione EURATOM-ENEA, ITALY

Dr. G. Grosso, Istituto di Fisica del Plasma, ITALY

Prof. G. Rostangni, Istituto Gas lonizzati Del Cnr, ITALY

Dr. H. Yamato, Toshiba Ros \& Dovel Conter, JAPAN
Prof. I. Kawakami, Hiroshima Univ., JAPAN

Prof. K. Nishikawa, Hiroshima Univ., JAPAN

Director, Japan Alomic Energy Research Inst., JAPAN

Prof. S. Itoh, Kyushu Univ., JAPAN

Research Info. Ctr., National Instit. for Fusion Sclence, JAPAN

Prot. S. Tanaka, Kyoto Univ., JAPAN

Librery, Kyoto Univ., JAPAN

Prof. N. Inowe, Univ. of Tokyo, JAPAN

Secrotary, Plasma Section, Electrotechnical Lab., JAPAN

S. Morl, Tectniced Advisor, JAERI, JAPAN

Dr. O. Miterai, Kumamoto Inst. of Technology, JAPAN

J. Hyeon-Sook, Korea Alomic Energy Plesearch Inst, KOREA

D.I. Choi, The Korea Adv. Inst. of Sal. \& Tech., KOREA

Prof. B.S. Lloy, Univ. of Waikato, NEW ZEALAND

Inst of Physics, Chinese Acad ScI PEOPLE'S REP. OF CHINA

Library, Inst. of Plasma Physics, PEOPLE'S REP. OF CHINA

Tringhua Univ. Library, PEOPLE'S REPUBLIC OF CHINA

Z. Li, S.W. Inst Physics, PEOPLE'S REPUBLIC OF CHINA

Prof. J.A.C. Cabral, Instituto Superior Tocnico, PORTUGAL

Dr. O. Petrus, ALI CUZA Univ., ROMANIA

Dr. J. de Villiers, Fusion Studies, AEC, S. AFRICA

Prof. M.A. Hellbarg, Univ. of Natal, S. AFRICA

Prof. D.E. Kim, Pohang Inst. of Sci. \& Tech., SO. KOREA

Prof. C.I.E.M.A.T, Fusion Division Library, SPAIN

Dr. L Sionflo, Univ. of UMEA, SWEDEN

Library, Royal Inst. of Technology, SWEDEN

Prof. H. Wilhelmson, Chaimers Univ. of Tech., SWEDEN

Centre Phys. Des Plasmas, Ecole Polytech, SWITZERLAND

Bibliotheok, Inst. Voor Plasma-Fysica, THE NETHERLANDS

Asst. Prof. Dr. S. Cakir, Middle East Tech. Univ., TURKEY

Dr. V.A. Glukhikh,Sci. Res. Inst. Eloctrophys.I Apparatus, USSR

Dr. D.D. Ryutov, Siberian Branch of Acadomy of Sal, USSA

Dr. G.A. Elieeov, I.V. Kurchatov Inst. USSR

Librarian, Tho Ukr.SSR Acadomy of Sciences, USSR

Dr. L.M. Kovrizhnykh, Inst. of General Physics, USSR

Kemforschungsanlage GmbH, Zentralbibliothek, W. GERMANY

Bibliothek, Inst. Fur Plasmaforschung, W. GERMANY

Prof. K. Schinder, Ruhr-Universitát Bochum, W. GERMANY

Dr. F. Wagner, (ASDEX), Max-Planck-Institut, W. GERMANY

Librarian, Max-Planck-Institut, W. GERMANY

Prof. R.K. Janev, Inst. of Physics, YUGOSLAVIA 

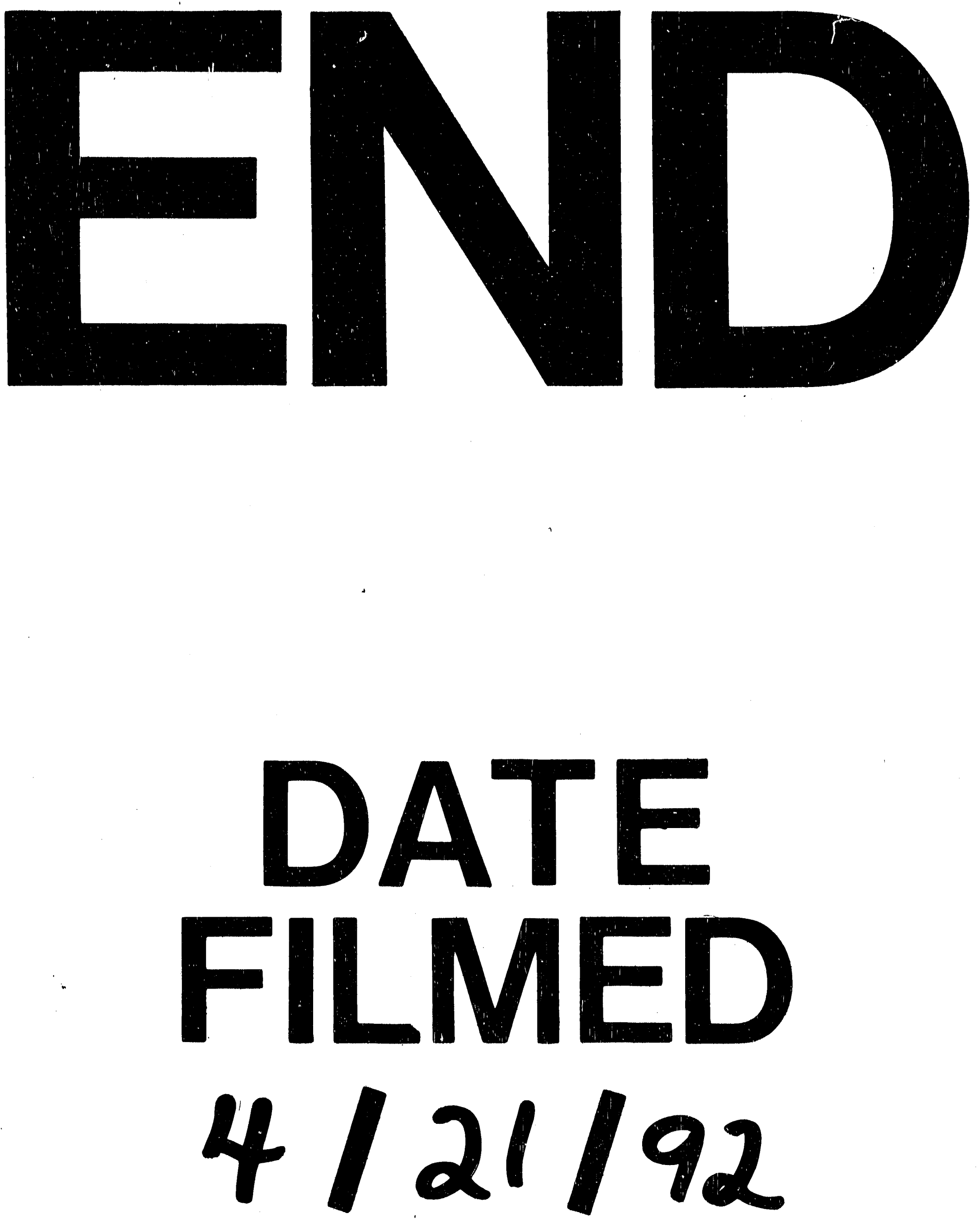
